AperTO - Archivio Istituzionale Open Access dell'Università di Torino

\title{
Evaluation of Serum Electrolytes and Blood Lactate Concentration During Repeated Maximal Exercise in Horse
}

\section{This is the author's manuscript}

Original Citation:

Availability:

This version is available http://hdl.handle.net/2318/1675782

since 2018-09-04T14:44:25Z

Published version:

DOI:10.1016/j.jevs.2014.07.001

Terms of use:

Open Access

Anyone can freely access the full text of works made available as "Open Access". Works made available under a Creative Commons license can be used according to the terms and conditions of said license. Use of all other works requires consent of the right holder (author or publisher) if not exempted from copyright protection by the applicable law. 
Original Research

\title{
Evaluation of Serum Electrolytes and Blood Lactate Concentration During Repeated Maximal Exercise in Horse
}

\author{
Anna Assenza DVM, PhD ${ }^{a}$, Domenico Bergero DVM ${ }^{\mathrm{b}}$, Fulvio Congiu DVM ${ }^{\mathrm{a}}$, \\ Francesco Tosto DVM, PhD ${ }^{\text {a }}$, Claudia Giannetto DVM, PhD ${ }^{\mathrm{a}}$, Giuseppe Piccione DVM ${ }^{\mathrm{a}, *}$

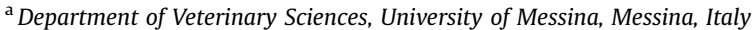 \\ ${ }^{\mathrm{b}}$ Department of Animal Production, Epidemiology and Ecology, University of Torino, Grugliasco (To), Italy
}

\section{A R T I C L E I N F O}

\section{Article history:}

Received 11 February 2014

Received in revised form 28 May 2014

Accepted 6 July 2014

Available online 11 July 2014

\section{Keywords:}

Serum electrolyte

Horse

Show jumping competition

Physical exercise

Blood lactate

\begin{abstract}
A B S T R A C T
Modifications of some serum electrolyte concentration during two international ${ }^{* * *}$ show jumping competition performed in two consecutive weekends were evaluated. Serum sodium $(\mathrm{Na})$, chloride $(\mathrm{Cl})$, magnesium $(\mathrm{Mg})$, potassium $(\mathrm{K})$, phosphorous $(\mathrm{P})$, calcium $(\mathrm{Ca})$, iron (Fe), and blood lactate on 14 well-trained Italian saddle horses were assessed. Blood samples were collected before the beginning of the competition (TOB), within 10 minutes after the end of race (R1, R2, and R3), and on the day after competition (TOR). The same procedure was followed on the second weekend (R4, R5, R6, and T1R). One-way repeated measures analysis of variance was applied on collected data, and a significant effect on sampling time $(P<.05)$ on all parameters studied was found. These results suggest that serum electrolytes and blood lactate concentration are responsive to intense exercise and could be considered an important factor for a correct management training's planning.
\end{abstract}

(c) 2014 Elsevier Inc. All rights reserved.

\section{Introduction}

Physical exercise involves many metabolic pathways and induces many physiological changes $[1,7,15,26]$. During an intense exercise, a great amount of fluid and electrolytes are lost through sweating $[11,12,23,24,30]$. This fluid loss, if prolonged in time, may cause hypovolemia, imbalance in electrolyte serum concentration, and when the deficit becomes serious, horses can show clinical signs of dehydration, and exercise performance can be compromised [21,22].

Water balance is fundamental for the correct physiological function of all organs $[17,18,25]$. Water, is involved in all biochemical reaction occurring in cells, and it is known as the main nutrients and waste products carrier. Otherwise, it provides for maintaining blood volume and thus the integrity of the cardiovascular system. Body water is

\footnotetext{
* Corresponding author at: Giuseppe Piccione, DVM, Department of Veterinary Sciences, University of Messina, Polo Universitario Dell'Annunziata, 98168, Messina, Italy.

E-mail address: giuseppe.piccione@unime.it (G. Piccione).
}

characterized by a specific electrolyte concentration, which is critical for several physiological processes [18,25,27]. Their constant concentration is essential for the regulation of osmotic pressure and to maintain multiple physiological processes in a correct way [30]. During exercise, there is a substantial fluid shift from plasma that establishes a change in electrolytic balance [21]. In particular, electrolytes such as sodium ( $\mathrm{Na})$, chloride $(\mathrm{Cl})$, magnesium $(\mathrm{Mg})$, potassium (K), phosphorous (P), calcium (Ca), and iron (Fe) are involved in several physiological processes, and their imbalance could lead a lowering of athletic performance.

Also, during maximal exercise, glucose is broken down through glycolysis to produce energy; when the oxygen supply to the cell is insufficient, pyruvate and hydrogen ions combine to form lactic acid. Lactic acid is a good energy source [14], but, if the intensity of exercise requires a maximal effort for a period of 20-120 seconds, it reached anaerobic threshold and blood lactate concentration tends to increase [6].

Sodium, chloride, magnesium, calcium, potassium, and phosphorus are important for the correct conduction of 
electrical impulse through nervous system and muscle and for the muscle contraction [10,19,32]; iron is important for oxygen blood-binding potential, otherwise lactate increment may cause muscular damage and pain [9,19]. Imbalance of serum electrolyte with concomitant increase of blood lactate concentration could be responsible for decline of athletic performances [23-25,28].

On the basis of this knowledge, the aim of the study was to investigate the changes in the concentration of some serum electrolytes in horses subjected to two international *** show jumping competition. The knowledge of metabolic changes that occur in horse during exercise is crucial to ensure a proper line of management of this animal. In particular, changes in the concentration of electrolytes may be a very useful parameter [16,33].

\section{Materials and Methods}

\subsection{Animals}

Fourteen regularly trained Italian saddle horses (eight geldings and six females; 8-15 years old; mean body weight, $500 \pm 25 \mathrm{~kg}$ ) were enrolled in this study with the informed owner consents. Before starting the study, horses were subjected to clinical examination, routine hematology, and biochemistry at rest conditions, and only healthy subjects were used. Animal were feed four times a day (7 AM, 11 AM, 3 PM, and 7 PM). Diet consisted of $6 \pm 1$ $\mathrm{kg} / \mathrm{d}$ hay (first cut meadow hay, sun cured, late cut, $6.9 \%$ crude protein on average) and $5 \pm 0.5 \mathrm{~kg} / \mathrm{d}$ concentrates (crude protein, 16\%; crude fat, 6\%; crude fiber, $7.35 \%$; ash, $10.09 \%$; sodium, $0.46 \%$; lysine, $0.85 \%$; methionine, $0.35 \%$; omega-3, 0.65\%); water was available ad libitum.

Horses took part in an international *** jumping competition "Sicilia jumping tour 2011" (Sicily latitude, $37.46 \mathrm{~N}$; longitude, 14.93E). Each session was preceded by 25-minute warm-up consisting in walk, trot, and gallop with six jumps (height from 100 to $140 \mathrm{~cm}$ ). All show jumping was performed at about the same hour in all day.

Race type, course length, obstacle height, and thermoigrometric recording are shown in Table 1 . All treatments, housing, and animal care reported previously were carried out in accordance with the standards recommended by the European Directive 2010/63/EU for animal experiments.

\subsection{Blood Sampling}

Blood samples were collected by jugular venipuncture in two different vacutainer tubes, containing clot activator and
EDTA, respectively, before the first competition day (TOB), within 10 minutes from the end of each exercise (R1, R2, and R3), and day after the competition (TOR); the same plan was followed during the second weekend (R4, R5, R6, and T1R). Samples collected in 9-mL vacutainer tubes with cloth activator (Terumo Corporation, Tokyo, Japan) were centrifuged at $1,300 \mathrm{~g}$ for 10 minutes, within 30 minutes of the collection, and the obtained serum was stored at $-20^{\circ} \mathrm{C}$. Sera were analyzed to assess sodium, chloride, magnesium, potassium, phosphorus, calcium, and iron by means of ultraviolet-visible spectrophotometry (Slim, SEAC, Italy). To assess blood lactate concentration, samples were collected in 3-mL vacutainer test tubes containing EDTA (Terumo Corporation). This allowed us to analyze the blood without the risk of clotting in the tube. Blood lactate was assessed by mean portable blood lactate analyzer (Accusport; Bohering, Germany) within 10 minutes from sample collection.

\subsection{Statistical Analysis}

All data are expressed as mean \pm standard error of the mean (SEM). One-way repeated measures analysis of variance (ANOVA) was used to determine statistically significant effects of exercise on serum electrolytes and blood lactate concentration in horses involved in this study. $P$ values $<.05$ were considered statistically significant. Bonferroni multiple comparison test was applied for post hoc comparison. Statistical analysis was performed using the STATISTICA software package (STATISTICA 7; Sat Software Inc, Tulsa, Oklahoma).

\section{Results}

Mean values \pm SEM of the parameters in the study are shown in Table 2. Based on ANOVA, there were significant effects of exercise on sodium $\left(F_{(8,104)}=158.8 ; P \leq .0001\right)$, iron $\left(F_{(8,104)}=11.15 ; P \leq .0001\right)$, magnesium $\left(F_{(8,104)}=\right.$ 18.87; $P \leq .0001)$, calcium $\left(F_{(8,104)}=59.31 ; P \leq .0001\right)$, phosphorus $\left(F_{(8,104)}=6.557 ; P \leq .0001\right)$, potassium $\left(F_{(8,104)}\right.$ $=19.74 ; P \leq .0001)$, chloride $\left(F_{(8,104)}=52.75 ; P \leq .0001\right)$, and lactate $\left(F_{(8,104)}=22.18 ; P \leq .0001\right)$.

In particular, Bonferroni multiple comparison test showed significant decrease of sodium in R2, R3, and TOR versus T0B and R1 and a significant increase of R4, R5, R6, and T1R versus R1, R2, and R3 (Fig. 1).

There was a significant decrease of chloride in $\mathrm{R} 2$ and $\mathrm{R} 3$ versus TOB and R1, a significant decrease of TOR versus TOB, and a significant increase in R4, R5, R6, and T1R of chloride concentration versus TOR, R2, and R3 (Fig. 1). A significant

Table 1

Race type, course length, obstacle height, and environmental conditions (ambient temperature [ ${ }^{\circ}$ ] and relative humidity [\% $\mathrm{RH}$ ]) recording during the two weekends of competition.

\begin{tabular}{|c|c|c|c|c|c|c|}
\hline \multirow[b]{2}{*}{$\begin{array}{l}\text { Experimental } \\
\text { conditions }\end{array}$} & \multicolumn{3}{|l|}{ Weekend 1} & \multicolumn{3}{|l|}{ Weekend 2} \\
\hline & Race Type & $\begin{array}{l}\text { Course and } \\
\text { Obstacle }\end{array}$ & $\begin{array}{l}\text { Ambiental } \\
\text { Environment }\end{array}$ & Race Type & $\begin{array}{l}\text { Course and } \\
\text { Obsatcle }\end{array}$ & $\begin{array}{l}\text { Ambiental } \\
\text { Environment }\end{array}$ \\
\hline First day & Two phases & $550 \pm 50 \mathrm{~m} ; 1.40 \mathrm{~cm}$ & $25 \pm 6^{\circ} \mathrm{C} ; 65 \pm 5 \% \mathrm{RH}$ & Two phases & $550 \pm 50 \mathrm{~m} ; 1.40 \mathrm{~cm}$ & $26 \pm 5^{\circ} \mathrm{C} ; 68 \pm 6 \% \mathrm{RH}$ \\
\hline Second day & $\begin{array}{l}\text { Mixed } \\
\text { competition }\end{array}$ & $550 \pm 50 \mathrm{~m} ; 1.45 \mathrm{~cm}$ & $27 \pm 4^{\circ} \mathrm{C} ; 66 \pm 3 \% \mathrm{RH}$ & $\begin{array}{l}\text { Mixed } \\
\text { competition }\end{array}$ & $550 \pm 50 \mathrm{~m} ; 1.45 \mathrm{~cm}$ & $28 \pm 3^{\circ} \mathrm{C} ; 70 \pm 5 \% \mathrm{RH}$ \\
\hline Third day & $\begin{array}{l}\text { Accumulator } \\
\text { competition }\end{array}$ & $550 \pm 50 \mathrm{~m} ; 1.40 \mathrm{~cm}$ & $24 \pm 5^{\circ} \mathrm{C} ; 70 \pm 3 \% \mathrm{RH}$ & $\begin{array}{l}\text { Accumulator } \\
\text { competition }\end{array}$ & $550 \pm 50 \mathrm{~m} ; 1.40 \mathrm{~cm}$ & $25 \pm 5^{\circ} \mathrm{C} ; 70 \pm 2 \% \mathrm{RH}$ \\
\hline
\end{tabular}




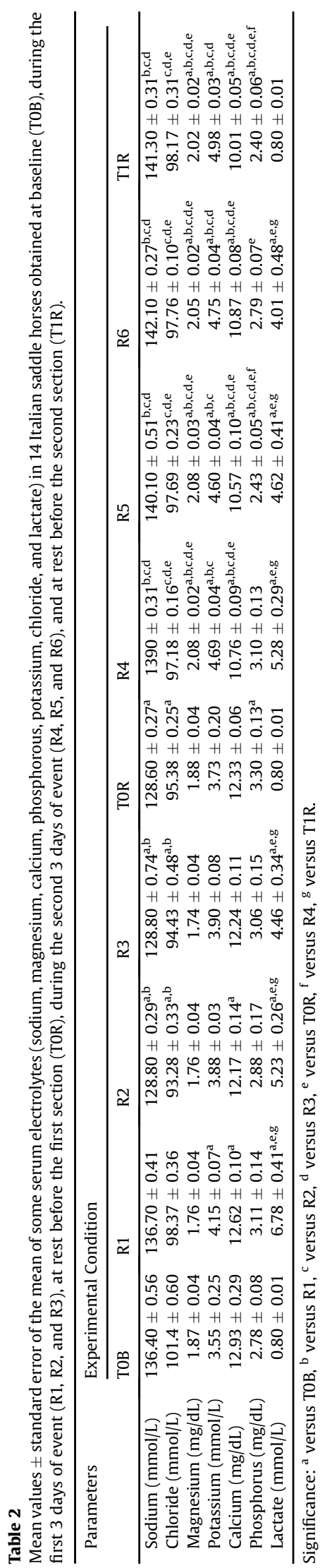

increase of magnesium in $R 4, R 5, R 6$, and T1R versus T0B, R1, R2, R3, and TOR was detected (Fig. 1). A significant increment in potassium was found in $\mathrm{R} 1$ versus TOB; $\mathrm{R} 4$ and $R 5$ versus TOB, R1, R2, and R6; and T1 R versus TOB, R1, R2, and R3 (Fig. 2). Calcium showed a significant decrease in R2 and $\mathrm{R} 3$ versus $\mathrm{TOB}$ and $\mathrm{R} 4, \mathrm{R} 5, \mathrm{R} 6$, and $\mathrm{T} 1 \mathrm{R}$ versus all experimental conditions (Fig. 2). Phosphorus showed a significant increase of TOR versus TOB and a significant decrease of R5 and T1R versus TOB, R1, R2, R3, TOR, and R4 and R6 versus TOR (Fig. 1). Analysis of variance showed a significant decrease in iron concentration at R4, R5, and R6 versus T0B, R1, R2, and R3 and a significant decrease in T1R versus all time points (Fig. 2). Lactate concentration (Fig. 3) showed a significant increase in R1-R6 versus resting time TOB, TOR, and T1R.

\section{Discussion}

The result obtained in the present study showed a significant effect of maximal exercise on sodium, chloride, magnesium, potassium, calcium, phosphorus, iron, and blood lactate concentrations. In particular, an effect of exercise was observed for sodium during the first 3 days of competition. It started to decrease in R2 and maintained this concentration until TOR. Fluid shift that occurs during exercise provokes a transmembrane movement of sodium that may reflect a negative water balance in the body and consequently a change in erythrocyte and muscle electrolyte concentrations $[28,29]$. During the second weekend of competition, the sodium level was the same as baseline level (TOB) and did not change statistically for the 3 days of completion (R4, R5, and R6) and T1R. Chloride showed statistically significant changes similar to sodium (Fig. 1). The increase of chloride concentration after exercise could be attributed to water balance. Its mechanism regulates the $\mathrm{pH}$ decrease due to exercise and consists in a plasma chloride ions movement from the blood plasma into the red blood cells in exchange for the bicarbonate [8]. This effect could justify the initial reduction of chloride during the first 3 days (Fig. 1; R1, R2, and R3) and return to baseline level at TOR. During the second weekend, a statistical increase of chloride with respect to R1, R2, and R3 was observed.

Magnesium concentration showed a trend similar to sodium and chloride with lower values during the first week of competition (R1, R2, and R3) with respect to TOB. In the recovery phase, magnesium concentration returned to the baseline level (TOB) and reached higher values during the second week and the last recovery phase (R4, R5, R6, and T1R). This concentration change could be explained through an initial loss, during the first week, of the ion with sweat. The absence of an effect of exercise during the weekend of competition in sodium, chloride, and magnesium concentrations could be because of an adaptation mechanism of sweat glands, which is known as short-term acclimation of sweat gland. In fact, it is demonstrated that sweat rate is higher and sodium concentration in sweat is lower during high temperature and high relative humidity (such as summer). Also, this mechanism is more efficient in well-trained horses whose sweat glands have a physiological adaptation to the sport [5]. The significant increase in potassium observed during the second 3 days of 

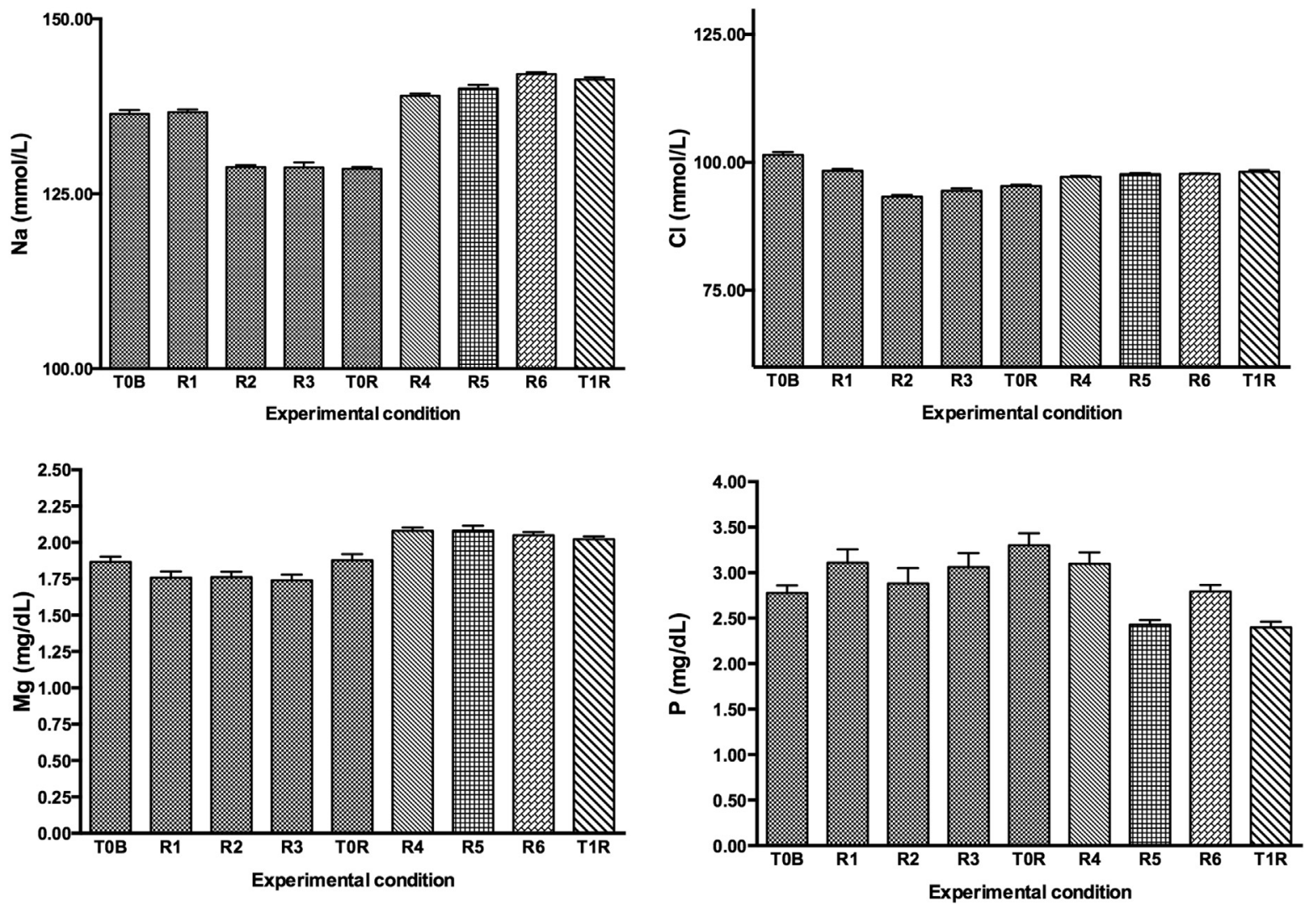

Fig. 1. The pattern of mean values ( \pm standard error) of some serum electrolytes (sodium [Na], chloride [Cl], magnesium [Mg], and phosphorous [P]) in 14 Italian saddle horses, the day before competition (TOB), 10 minutes after the race for three days (R1, R2, and R3), the first rest day (TOR), 10 minutes after the second session of competition (R4, R5, and R6), and the second rest day (T1R).

competition (R4, R5, and R6) could be attributed to the losses that occur from muscle fibers. During exercise, not all muscle fibers are involved in the muscular effort, but some remain inactive and are appointed to dispose of excess potassium. With increasing muscular effort, the number of fibers recruited increase with consequent depletion methods to dispose the excess ion and then hyperkalemia occurs [13]. This effect could justify the potassium increase in the second weekend by proximity of the two races, only 5 days, and the difficulty of the races (Concours the Saud International ${ }^{* * *}$ ) that brings the animal to use an increasing number of muscle fibers. Plasma potassium concentration reached a plateau after an exercise greater than 2 minutes; this equilibrium is regulated by catecholamines, in particular, fibers that are under $\beta_{2}$-adrenergic receptor control, such as inactive muscle. In T1R, potassium concentration did not lower in blood. This decrease is probably caused by an ineffective reuptake mechanism into muscles that are fatigued and need more time to absorb the excess potassium [20].

Calcium and phosphorus showed a lower concentration value during the second week and the last recovery phase with respect to the first week and baseline level. This diminution could be the result of an increased urinary mineral excretion, greater endogenous fecal excretion, and decreased mineral absorption efficiency in the intestine
[10]. Another possible cause could be that, in the course of exercise, decreases production of parathyroid hormone by parathyroid glands [2]. The decrease in plasma level of the hormone leads to a decrease in free calcium and phosphorus levels.

Iron showed a continuous decrease in ion concentration (Fig. 2) related to the amount of continuing losses and the relative slowness of ion absorption from the gastrointestinal tract [4]. The losses are caused by increased urinary excretion and, minimally, sweat and microbleeds. In fact, because of the anatomic shape of the respiratory system of the horse and the physiology of breathing (compulsive nasal breathing and coupling locomotion-breathing), there is a drastic increase in alveolar pressure level with the possibility of rupture of capillaries [3].

At the beginning of the study, horses showed a lactate concentration of about $0.5 \mathrm{mmol} / \mathrm{L}$, this condition is repeated in all subjects tested (Table 1 ). The show jumping is an activity that engages the anaerobic pathway for energy production in the muscle, resulting in increased plasma concentrations of lactate. The increment of lactate and maintaining at high levels is observed throughout all days of competition with a peak in the early days (R1 and R4). During R2 and R3, there was a gradual lactate decrease because of the increase of lactate utilization and metabolic shift. These phases of decrease in blood lactate can be 

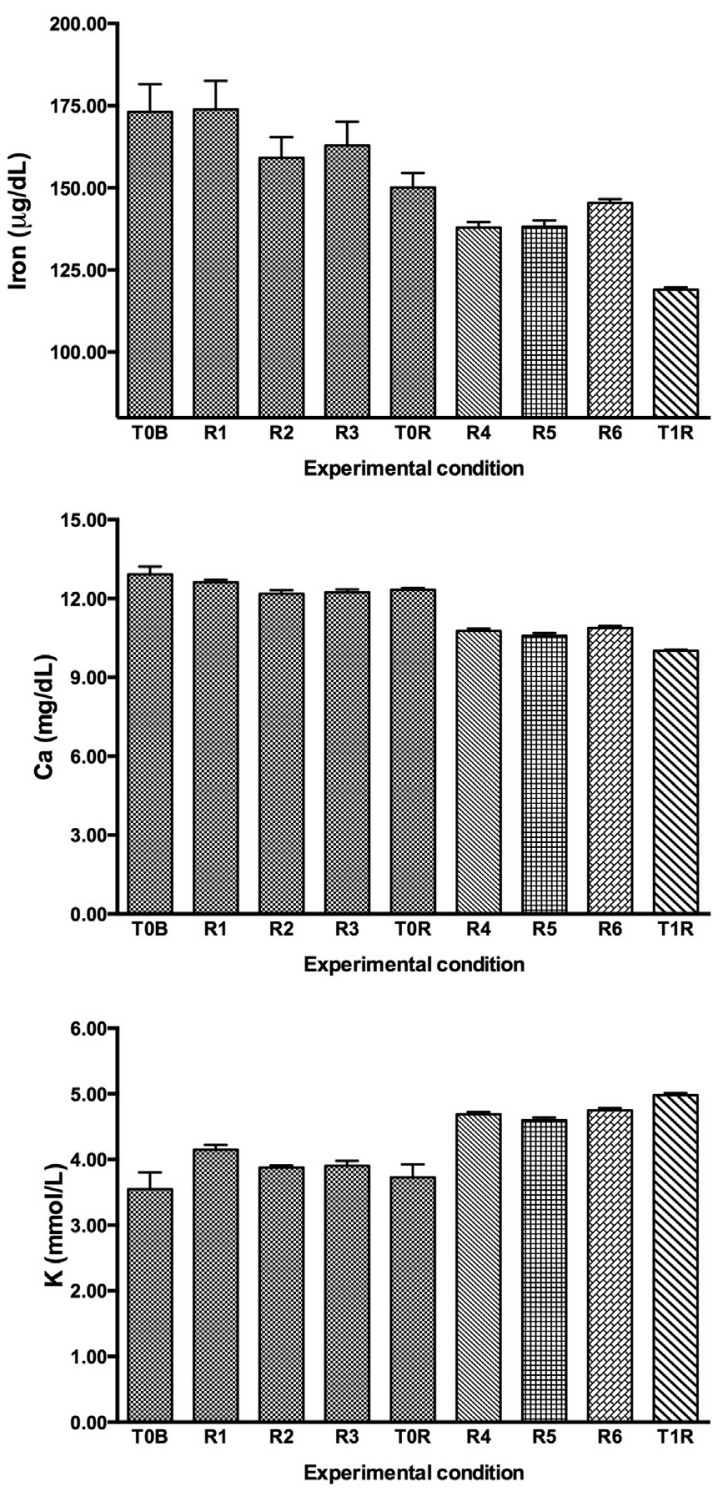

Fig. 2. The pattern of mean values ( \pm standard error) of some serum electrolytes (iron, calcium [Ca], and potassium [K]) in 14 Italian saddle horses, the day before competition (TOB), 10 minutes after the race for three days (R1, R2, and R3), the first rest day (TOR), 10 minutes after the second session of competition (R4, R5, and R6), and the second rest day (T1R).

interpreted as recovery interphase [13,31]. The rapid decline of lactate concentration observed during the recovery phase (TOR and T1R) was because of a rapid reuptake and use by liver and muscle of lactate for energy production through Krebs cycle. The speed whereby the animal disposes lactate to replenish glycogen stores was a sign of good workout management [9,31]. The good state of training of the horses was confirmed by the fall in concentration of lactate during recovery.

\section{Conclusions}

The results showed the effect of two race sessions on values of serum electrolytes that may reflect state of

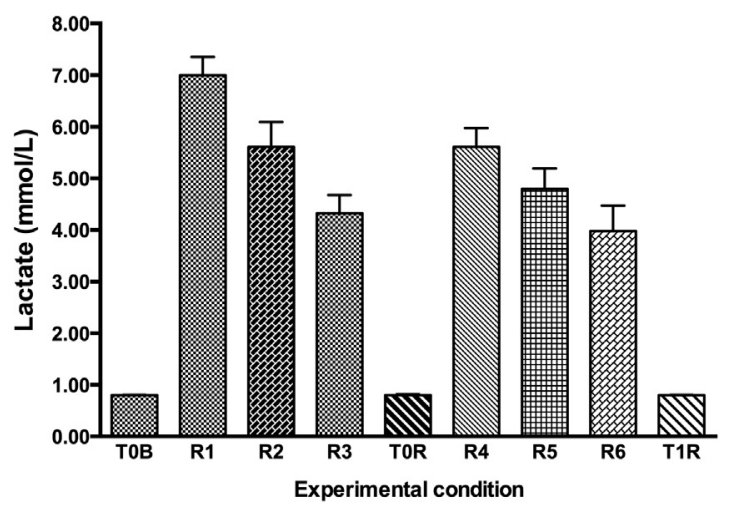

Fig. 3. The pattern of mean values ( \pm standard error) of lactate in 14 Italian saddle horses, the day before competition (TOB), 10 minutes after the race for three days (R1, R2, and R3), the first rest day (TOR), 10 minutes after the second session of competition (R4, R5, and R6), and the second rest day (T1R).

hydration of the animal, state of fatigue of the animal, the recovery time, and the workload management. Electrolytes vary from the baseline during race session, and the trends are dissimilar in the second weekend. In an ideal condition of training, we had two overlapping patterns, but the occurrence of events such as muscle fatigue, stress induced by the proximity of the two races, inevitably leads to these differences. The lactate levels at T1R lowered to the same concentrations recorded at TOR demonstrating that the horses were well-trained. However, the changes in serum electrolyte concentrations observed in our study suggest that the administration of dietary electrolyte supplements might help in preventing the onset of the fatigue when horses perform specific training programs. Hence training assumes a central role in a plane of correct sporting management of the animal: making metabolic pathway more efficient (using aerobic pathway), cardiovascular system adjustment more competitive (basal bradycardia, more efficient glomerular filtration, and less bleeding due to extreme vasoconstriction), and minor sweating due to heat production diminution (best energy utilization). However, more studies should be conducted to better understand the mechanism of regulation of electrolytes in the athletic horse.

\section{References}

[1] Adamu L, Adzahan M, Abdullah R, Ahmad B. Effects of race distance on physical, hematological and biochemical parameters of endurance horses. Am J An Vet Sci 2010;5(4):244-8.

[2] Aguilera-Tejero E, Estepa JC, López I, Bas S, Garfia B, Rodríguez M. Plasma ionized calcium and parathyroid hormone concentrations in horses after endurance rides. J Am Vet Med Assoc 2001;219(4): 488-90.

[3] Art T, Lekeux P. Exercise-induced physiological adjustments to stressful conditions in sports horses. Livest Prod Sci 2005;92: $101-11$.

[4] Assenza A, Tosto F, Casella S, Fazio F, Giannetto C, Piccione G. Changes in blood coagulation induced by exercise training in young athletic horses. Res Vet Sci 2013;95:1151-4.

[5] Bates GP, Miller VS. Sweat rate and sodium loss during work in the heat. J Occup Med Toxicol 2008;3:4.

[6] Bergero D, Assenza A, Caola G. Contribution to our knowledge of the physiology and metabolism of endurance horses. Livest Prod Sci 2005;92:167-76. 
[7] Clayton HM. Condition sport horses. Sasketchewan, Canada: Sport Horse Publication; 1991. p. 45-60.

[8] Coenen M. Exercise and stress: impact on adaptive processes involving water and electrolytes. Livest Prod Sci 2005;92:131-45.

[9] Carlson GP, Jones JH. Effects of frusemide on electrolyte and acidbase balance during exercise. Equine Vet J 1999;30:370-4.

[10] Dittricht N, DeLucas D, Franzoni Maioral M, Diefenthaeler F, Guilherme L, Guglielmo A. Continuous and intermittent running to exhaustion at maximal lactate steady state: neuromuscular, biochemical and endocrinal responses. J Sci Med Sport 2013;16: 545-9.

[11] Dressendorfer RH, Petersen SR, Lovshin SE, Keen CL. Mineral metabolism in male cyclists during high-intensity endurance training. Int J Sport Nutr Exerc Metab 2002;12:63-72.

[12] Foreman J, Waldsmith J, Lalum R. Physical, acid-base and electrolyte changes in horses competing in training, preliminary and immediate horse trials. Equine Comp Exerc Physiol 2004;1(2):99-105.

[13] Gatta D, Magni L, Baragli P, Ciattini F, Luccardi AP, Colombani B. Le variazioni degli elettroliti nel siero e nel sudore di cavalli da endurance impegnati in test di sforzo submassimale su treadmill. SIDI; 1998. p. 3-15.

[14] Harris P, Snow DH. Plasma potassium and lactate concentration in thoroughbred horse during exercise of varying intensity. Equine Vet J 1992;23:220-5.

[15] Hodgson DR, Rose RJ. The athletic horse. Philadelphia: Saunders; 1994.

[16] Hura V, Novotný F, Boldižár M, Rédl M, Noskovičová J, Horñák S, Petrovič V, Lazar G, Kováč G. Biochemical responses to a nonstandard exercise in horses trained for jumping. Acta Vet Brno 2013;82:161-7.

[17] Hyypa W, Poso RA. Fluid, electrolyte, and acid-base responses to exercise in racehorse. Vet Clin North Am Equine Pract 1998;14:121-35.

[18] Kaneko JJ, Harvey JW, Bruss ML. Clinical biochemistry of domestic animals; 2008. p. 530-54.

[19] Kinnunen S, Hyyppa S, Lappalainen Jani, Oksala N, Venojärvi M, Nakao C, Hänninen Osmo, Sen CK, Atalay M. Exercise-induced oxidative stress and muscle stress protein responses in trotters. Eu J App Phys 2004;93(4):496-501.

[20] Lawrence LA. Effects of exercise and training on skeletal development in horses. In: Pagan JD, editor. Advances in equine nutrition III; 2005. p. 219-26.
[21] Maïmoun L, Sultan C. Effect of physical activity on calcium homeostasis and calcitropic hormones: a review. Calcif Tissue Int 2009;85:277-86.

[22] Melbø JI, Sejersted OM. Plasma potassium changes with high intensity exercise. J Physiol (lond) 1990;421:105-22.

[23] Muñoz A, Cuesta I, Riber C, Gata J, Trigo P, Castejóon FM. Trot asymmetry in relation to physical performance and metabolism in equine riders. Equine Vet J 2006;36:50-4.

[24] Muñoz A, Riber C, Trigo P, Castejón F. Hematology and clinical pathology data in chronically starved horse. J Equine Vet Sci 2010a;30: 581-9.

[25] Piccione G, Giannetto C, Assenza A, Fazio F, Caola G. Serum electrolyte and protein modification in jumper horse. Comp Clin Pathol 2007;16:103-7.

[26] Piccione G, Casella S, Giannetto C, Messina V, Monteverde V, Caola G, Guttadauro S. Haematological and haemochemical responses to training and competition in standardbred horses. Comp Clin Pathol 2010;19:95-101.

[27] Pritchard JC, Burn CC, Barr ARS, Helen RW. Haematological and serum biochemical reference values for apparently healthy working horses in Pakistan. Res Vet Sci 2009;87:389-95.

[28] Sawaka MN. Body fluid response and hypohydration during exercise-heat stress. In: Pandolf KB, Sawaka MN, Gonzalez RR, editors. Human performance physiology and environmental medicine at terrestrial extremes. Cooper publishing group; 1988. p. 227-66.

[29] Sawaka MN. Physiological consequence of dehydration: exercise performance and thermoregulation. Med Sci Sports Exercs 1992;24: 657-70.

[30] Sawaka MN, Montain SJ. Fluid and electrolyte supplementation for exercise heat stress. Am J Clin Nutr 2000;72s:564S-72S.

[31] Saxton DR, Seldin DW. Clinical interpretation of laboratory valves. In: Kokko JP, Tannen RL, editors. Fluids and electrolytes. Philadelphia, PA: Saunders; 1996. p. 3-62.

[32] Scoppetta F, Tartaglia M, Renzone G, Avellini L, Gaiti A, Scaloni A, Chiaradia E. Plasma protein changes in horse after prolonged physical exercise: a proteomic study. J Proteomics 2012;75:4494504.

[33] Von Wittke P, Lindner A, Deegen E, Sommer H. Effects of training on blood lactate-running speed relationship in thoroughbred racehorses. J App Physiol 1994;77:298-302. 